\title{
Endothelin-1 Antagonist in the Management of Refractory Systemic Hypertension in Children with End Stage Kidney Disease: A Case Series
}

\author{
Jayanthi Chandar*, Wacharee Seeherunvong, Carolyn Abitbol, Chryso Katsoufis, \\ Alcia Edwards-Richards, Teresa Cano, Gastón Zilleruelo \\ Department of Pediatrics, Division of Pediatric Nephrology, Holtz Children's Hospital, University of Miami \\ Miller School of Medicine, Miami, USA \\ Email: ${ }^{*}$ jchanda2@med.miami.edu
}

Received 11 March 2014; revised 15 April 2014; accepted 23 April 2014

Copyright (C) 2014 by authors and Scientific Research Publishing Inc. This work is licensed under the Creative Commons Attribution International License (CC BY). http://creativecommons.org/licenses/by/4.0/

c) (i) Open Access

\begin{abstract}
Uncontrolled hypertension is a significant problem in children with end stage kidney disease. We studied 10 children on chronic hemodialysis who received the endothelin-1 receptor antagonist, bosentan as adjunctive therapy in refractory systemic hypertension. Data were retrospectively analyzed on systolic (SBP) and diastolic blood pressure (DBP), antihypertensive medications and hospitalization days per patient per year, at baseline and 3 months after initiation of bosentan. The standard deviation (Z) score of BP for age, height and gender was calculated. Mean age and weight of these children were 11.4 \pm 4.8 years (range 1 - 17.5 years) and $32.9 \pm 14.4 \mathrm{~kg}$ (range 7.4 $57 \mathrm{~kg}$ ) respectively and $90 \%$ were African American. Seven were on hemodialysis $\geq 4$ times weekly. The average inter-dialytic weight gain was $4.7 \% \pm 1.8 \%$. The pre-dialysis SBP and DBP $Z$ scores were $4.9 \pm 1.8$ and $4.0 \pm 1.0$ at baseline and decreased to $1.3 \pm 0.4$ and $1.3 \pm 0.8,3$ months after initiation of bosentan $(p<0.0001)$. Similarly, anti-hypertensive medications were decreased from 5 \pm 1.5 to $2.1 \pm 2.6(\mathrm{p}<0.01)$. Hospitalization days decreased from $35.6 \pm 52.4$ days to $1.5 \pm 3.3$ days $(p<0.0001)$. This preliminary report indicates bosentan may be beneficial in the management of children with severe refractory hypertension.
\end{abstract}

\section{Keywords}

Children, End Stage Kidney Disease, Hypertension, Bosentan

\footnotetext{
*Corresponding author.

How to cite this paper: Chandar, J., et al. (2014) Endothelin-1 Antagonist in the Management of Refractory Systemic Hypertension in Children with End Stage Kidney Disease: A Case Series. World Journal of Cardiovascular Diseases, 4, $217-224$. http://dx.doi.org/10.4236/wjcd.2014.45029
} 


\section{Introduction}

Hypertension is a significant problem in children with end stage kidney disease (ESKD) [1]-[3]. Uncontrolled hypertension is an important risk factor for cardiovascular disease [4]-[6]. African American race, young age, primary diagnosis of acquired kidney disease and chronic hemodialysis are some risk factors for severe hypertension in this population [7]. Nephrectomy is sometimes considered in patients with severe refractory hypertension of renal origin, and this should result in control of blood pressure (BP), if fluid and sodium intake are controlled [8]. However, hypertension may persist after nephrectomy (renoprival hypertension) despite control of volume and sodium intake, and multiple anti-hypertensive medications are required [9].

Angiotensin II receptor type 1 (AT1) receptors are ubiquitously expressed in the body. A proposed mechanism of hypertension in ESKD is, the peripheral vascular and possibly central nervous system effects of Angiotensin II, potentiating the mitogenic action of endothelin-1 (ET-1) resulting in smooth muscle hypertrophy [10]-[12]. Bosentan is an ET-1 receptor blocker which has been used in clinical trials in adults for treatment of systemic hypertension, but has not been studied in children with systemic hypertension [13]. Based on its potential to lower blood pressure, it was used as adjunctive therapy in a few of our patients with severe hypertension and ESKD who were refractory to multiple anti-hypertensive medications, despite adequate fluid removal by dialysis and bilateral nephrectomy in some of them. These were children who had considerable morbidity from their hypertension including seizures, cardiac failure, stroke and prolonged hospitalization in the intensive care unit. The objective of this study was to determine the effectiveness of the ET-1 receptor blocker, bosentan, in the management of refractory systemic hypertension in our small case series of children with ESKD.

\section{Methods}

A retrospective analysis was performed in 10 children with ESKD, less than 21 years of age with severe refractory hypertension and treated with the endothelin-1 receptor blocker, bosentan at the University of Miami/Holtz Children's Hospital from June 2003 to June 2011. The study was approved by the Institutional Review Board with waiver of consent authorization. All subjects were assured anonymity in compliance with the Health Insurance Portability and Accountability Act (HIPAA). Baseline data included demographics, anthropometrics, age at initiation of dialysis, cause of ESKD, anti-hypertensive treatment, number of dialysis sessions per week, hospitalizations for complications of hypertension and history of nephrectomy. Selected diagnostic parameters such as calcium, phosphorous, intact parathyroid hormone (PTH) and echocardiographic results were collected. Data on pre and post-dialysis sitting measurements of BP at the third or fourth dialysis session of the week, estimated dry weight and inter-dialytic weight gain were obtained. The criteria for determining dry weight included the lowest weight each patient could tolerate without developing symptoms of excessive fluid removal such as hypotension or cramps, taking into consideration changes in patient's nutritional status [14]. Percent fluid weight gain was determined by taking the average of 3 inter-dialytic weight gain measurements and expressing this as a percentage of the estimated dry weight.

Pre and post dialysis sitting BP measured by the oscillometric method were used for this study. Pre-dialysis BP measurements were obtained prior to initiation of dialysis and post-dialysis measurements were obtained 5 10 minutes after the patient's blood was returned. Mean of three BP measurements were obtained on each patient prior to, and at 1 and 3 months after initiation of bosentan. The third or fourth dialysis session was chosen to minimize the effect of excessive weight gain associated with longer inter-dialytic periods. The standard deviation or Z score was calculated by subtracting the expected (50th percentile) BP for age, gender and height from the actual BP and dividing it by the standard deviation. Hypertension was defined as average systolic (SBP) and diastolic blood pressure (DBP) >95th percentile for age, gender and height [15]. Stage 2 hypertension was defined as SBP and DBP that is $5 \mathrm{mmHg}$ above the 99th percentile for age, gender and height [15]. Severe hypertension was defined as BP which was $20 \mathrm{mmHg}$ above the 95th percentile [16]. Refractory hypertension was defined as uncontrolled severe hypertension, despite adequate fluid removal and treatment with 3 or more antihypertensive medications. Children who fulfilled these criteria and in whom Bosentan was used as adjunctive therapy were included in this analysis. Bosentan was not considered in children with hypertension controlled by dialysis and standard anti-hypertensive medications, and were therefore excluded from this analysis.

The mean value of 3 measurements of calcium, phosphorous and intact PTH were obtained from the initial routine monthly hemodialysis laboratory studies. Secondary hyperparathyroidism was defined as an intact PTH $>300$ pg/ml [17]. Results of two-dimensional and M-mode echocardiograms performed using standard 
techniques, were recorded. Left ventricular mass index (LVMI) was determined by dividing the left ventricular mass (grams) by the patient's height $(\mathrm{cm})^{2.7}$. Left ventricular hypertrophy $(\mathrm{LVH})$ was defined as LVMI $>95$ th percentile for height age and gender [18].

The dose of bosentan was $62.5 \mathrm{mg}$ twice daily for patients weighing $>30 \mathrm{~kg}, 31.25 \mathrm{mg}$ twice daily for those $10-30 \mathrm{~kg}$, and $15.6 \mathrm{mg}$ twice daily for the infant weighing $<10 \mathrm{~kg}$. Dosing was based on the experience in children with pulmonary hypertension [19]. Results of liver enzyme studies were recorded at baseline and every month during therapy.

The primary outcomes of interest were determination of magnitude of decline in systolic and diastolic BP Z scores from baseline to 1 month and 3 months after initiation of therapy with bosentan. Secondary outcome measures were hospitalization days and number of anti-hypertensive drugs used.

\section{Statistical Analysis}

Descriptive statistics were used to summarize data. Continuous variables were expressed as mean \pm SD. Blood pressure was expressed as the Z score. Differences in pre and post dialysis SBP and DBP over time were analyzed by one way analysis of variance. The relationship between biochemical parameters and baseline blood pressures, and age and inter-dialytic weight gain were analyzed by linear regression. Differences in LVMI and hospitalization days at baseline, and after initiation of treatment were analyzed by student's $t$ test. The Wilcoxon matched pairs test was used to compare the number of anti-hypertensive agents used at baseline and 3 months. p values of $<0.05$ were considered significant. All graphs and statistical analysis were performed using Graphpad® version 5 for windows (San Diego, California, USA. www.graphpad.com).

\section{Results}

Ten children with a mean age of $11.4 \pm 4.8$ years (range 1 - 17.5 years) had severe refractory hypertension between the years June 2003 to June 2011. The majority (9/10) of those that required therapy were African American, 1 was Caucasian and 6 were males. The primary diagnosis was focal segmental glomerulosclerosis (FSGS) in 3, membranoproliferative glomerulonephritis (MPGN) in 1, Lupus nephritis in 2, failed transplant in 2, cystic kidney disease in 1, and kidney carcinoma in 1. Bilateral nephrectomy was performed in 5 of 10 children of whom 2 had FSGS, 1-MPGN, 1-kidney carcinoma and 1 had cystic kidney disease. Seven patients required hemodialysis $\geq 4$ times weekly to achieve their estimated dry weight and to ensure that volume overload was not a contributing factor to refractory hypertension (Table 1). The average time on dialysis was $9.6 \pm 6.9$ months (range 0.5 to 20 months). Mean weight of the children was $32.9 \pm 14.4 \mathrm{~kg}$ (range $7.4-57 \mathrm{~kg}$ ). Overall, the mean inter-dialytic percent weight gain was $4.7 \% \pm 1.8 \%$ and was not significantly different from baseline and 3 months after initiation of bosentan with the exception of one child who consistently had high inter-dialytic weight gain (Table 1). Younger children had a greater increase in inter-dialytic percent weight gain in relation to their body size in comparison to older children $(\mathrm{p}<0.003)$.

\section{Mean Blood Pressure Z Scores}

Prior to initiation of therapy with bosentan, the average Z scores of pre-dialysis SBP and DBP were $4.9 \pm 1.8$ and $4.0 \pm 1.0$ respectively. At baseline, fluid removal did have a significant effect on both SBP and DBP but post-dialysis SBP and DBP Z scores were still significantly elevated ( $3.8 \pm 0.4$ and $3.1 \pm 0.2$ respectively). Forty percent of this cohort had a paradoxical increase in BP during dialysis.

Figure 1(a) and Figure 1(b) demonstrate BP Z scores at baseline, 1 month and 3 months after initiation of therapy with bosentan. There was a significant decline in SBP and DBP Z scores at 1 and 3 months after therapy. There was a significant difference in pre and post-dialysis SBP at baseline $(\mathrm{p}<0.01)$ but not at 1 and 3 months after initiation of bosentan. The value of pre and post dialysis SBP reached <90th percentile at 1 and 3 months from baseline and DBP reached 90 - 95th percentile.

\section{Laboratory and Echocardiographic Parameters}

Initial mean calcium, phosphorous, and intact PTH were $9.3 \pm 0.8 \mathrm{mg} / \mathrm{dl}, 5.6 \pm 1.3 \mathrm{mg} / \mathrm{dl}$ and $427 \pm 434$ picogram $/ \mathrm{ml}$ respectively. There was a significant correlation between baseline pre-dialysis SBP Z score and intact PTH ( $<0.02$; Spearman $R=0.74$ ). There were no significant changes in liver enzymes after the institution of 
Table 1. Patient characteristics.

\begin{tabular}{|c|c|c|c|c|c|c|c|c|c|c|c|}
\hline \multirow{3}{*}{ Patient } & \multirow[b]{3}{*}{ Age (years) } & \multirow{2}{*}{\multicolumn{2}{|c|}{$\begin{array}{l}\text { Number of dialysis } \\
\text { sessions }\end{array}$}} & \multirow{2}{*}{\multicolumn{2}{|c|}{$\begin{array}{l}\text { Percent weight gain } \\
\text { (\%) }\end{array}$}} & \multicolumn{4}{|c|}{ Post-dialysis BP Z scores } & \multirow{2}{*}{\multicolumn{2}{|c|}{$\begin{array}{c}\text { Number of } \\
\text { anti-hypertensives }\end{array}$}} \\
\hline & & & & & & \multicolumn{2}{|c|}{ Baseline } & \multicolumn{2}{|c|}{3 months } & & \\
\hline & & Baseline & 3 months & Baseline & 3 months & SBP & DBP & SBP & DBP & Baseline & 3 months \\
\hline 1 & 12.5 & 4 & 3 & 2.1 & 7.0 & 3.29 & 3.2 & 1.55 & 2.86 & 5 & 2 \\
\hline 2 & 13.5 & 3 & 3 & 5.3 & 5.1 & 2.70 & 2.28 & 1.45 & 1.10 & 4 & 2 \\
\hline 3 & 17.5 & 3 & 3 & 5.3 & 3.8 & 1.83 & 2.30 & -0.19 & 1.71 & 3 & 1 \\
\hline 4 & 13.5 & 4 & 3 & 2.7 & 3.3 & 4.55 & 4.30 & 0.68 & 0.64 & 5 & 0 \\
\hline $5 \infty$ & 5.5 & 4 & 4 & 5.7 & 11.9 & 3.48 & 3.48 & 1.45 & 2.65 & 8 & 8 \\
\hline 6 & 12 & 4 & 3 & 3.1 & 4.2 & 4.20 & 3.12 & 0.37 & 0.95 & 5 & 3 \\
\hline 7 & 12 & 4 & 3 & 6.3 & 4.8 & 4.83 & 3.90 & 0.87 & 0.87 & 4 & 0 \\
\hline 8 & 10.5 & 4 & 3 & 6.7 & 2.8 & 5.30 & 3.54 & 0.46 & 1.47 & 5 & 5 \\
\hline 9 & 15.5 & 3 & 3 & 2.8 & $2.8^{*}$ & 2.74 & 2.92 & $0.37^{*}$ & $0.64^{*}$ & 4 & $0^{*}$ \\
\hline 10 & 1 & 6 & 4 & 7.2 & 6.9 & 4.66 & 1.99 & 1.19 & 1.65 & 7 & 0 \\
\hline Mean \pm SD & $11.4 \pm 4.8$ & $3.9 \pm 0.9$ & $3.2 \pm 0.4^{*}$ & $4.7 \pm 1.8$ & $5.5 \pm 2.8$ & $3.8 \pm 1.1$ & $3.1 \pm 0.7$ & $0.8 \pm 0.6 \dagger$ & $1.6 \pm 0.8 \dagger$ & $5 \pm 1.5$ & $2.1 \pm 2.6^{\bullet}$ \\
\hline
\end{tabular}

*BP and medications at 1 month; transferred care after that; ${ }^{\infty} \mathrm{High}$ inter-dialytic weight gain probably contributed to persistence of significant hypertension; 95 percentile for $\mathrm{BP}=1.645$ SD from the mean; ${ }^{*} \mathrm{p}<0.01 ;{ }^{\dagger} \mathrm{p}<0.001 ;{ }^{\dagger} \mathrm{p}<0.01$ (anti-hypertensives include Bosentan).

Comparison of Pre and Post Dialysis Systolic BP

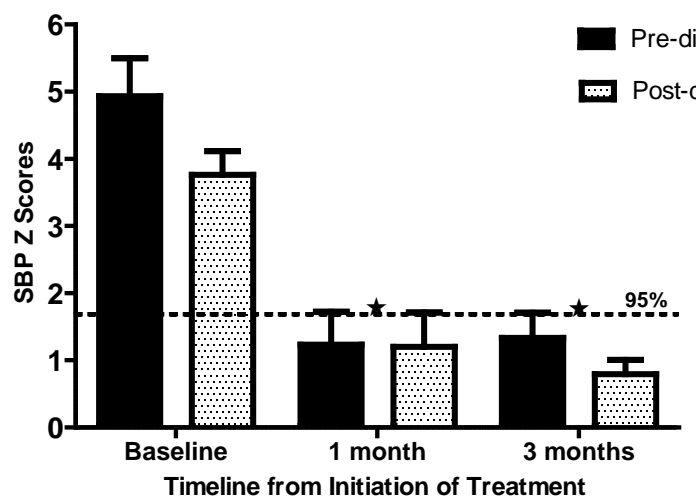

$\star p=0.0001$-baseline to 1 month and 3 months

(a)
Comparison of Pre and Post Dialysis Diastolic BP

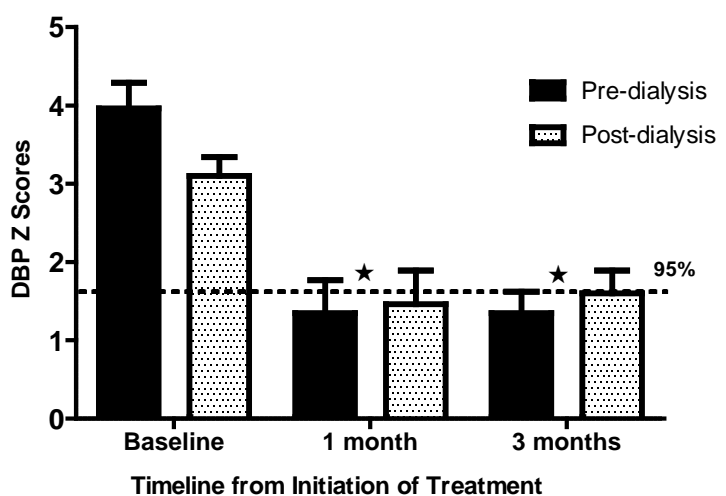

$\star p=0.0001$-baseline to 1 month and 3 months

(b)

Figure 1. Pre and post dialysis systolic and diastolic BP Z scores at baseline, 1 month and 3 months after initiation of bosentan. At baseline, blood pressures were severe pre and post dialysis. At one and 3 months there is a significant decline in $\mathrm{Z}$ scores. There was a significant difference in pre and post dialysis SBP and DBP at baseline with fluid removal, but not at 1 and 3 months after initiation of Bosentan..

treatment with bosentan. There was a downward trend in LVMI Z scores before (2.2 \pm 0.9$)$ and after treatment (1.4 \pm 0.4) in 7 patients who had objective measurements of LVMI available. However, this was not statistically significant.

\section{Anti-Hypertensive Drug Use and Hospitalization Rate}

In 8 of 10 children, the average time for significant blood pressure control and decrease in number of antihypertensive agents including bosentan was $1.75 \pm 0.9$ months (Table 1 ). The average duration of therapy with Bosentan was $10 \pm 7.7$ months in these 8 children. However, there was difficulty decreasing anti-hypertensive agents in 2 children. Hypertension in one of these was attributed to high inter-dialytic weight gain (Table 1). Hospitalization days per patient per year for hypertensive crisis decreased from $35.6 \pm 52.4$ days (median-22.5) 
prior to initiation of bosentan to $1.5 \pm 3.3$ days (median -0$)$ after initiation of treatment $(\mathrm{p}<0.0001)$.

\section{Discussion}

Bosentan has been effectively used for treatment of pulmonary hypertension in children [19]. However, this is the first report of its use in systemic hypertension in children. Bosentan was considered as a last resort in these children with ESKD who suffered significant morbidity from refractory and severe hypertension despite increasing frequency of fluid removal and use of multiple anti-hypertensive medications. The addition of bosentan to the anti-hypertensive regimen resulted in a significant decline in blood pressure occurring over a 2 to 3 month period, ultimately enabling a reduction in the number of anti-hypertensive agents used, and significantly reducing the hospitalization days from hypertensive crisis.

The beneficial effect of bosentan for essential hypertension was first described in adults [13]. Vascular smooth muscle hypertrophy and increased tissue expression of ET-1 has been demonstrated in human hypertension and in various animal models [20]-[23]. However, plasma endothelin levels are usually normal in hypertension, although relatively elevated in hypertensive African Americans [24]. Improvement in vascular smooth muscle cell hypertrophy and endothelial function has been noted after the use of ET-1 antagonists [25] [26]. This may be one of the hypothesized mechanisms for blood pressure improvement in these patients.

The prevalence of hypertension is as high as $74 \%$ in children on chronic hemodialysis and is uncontrolled even on anti-hypertensive treatment in the majority of this population [1]-[3]. In this study, younger children had a greater increase in percent fluid weight gain which may be partly related to their dependence on fluid nutrition and therefore required greater frequency of dialysis. One of the goals of dialysis is to achieve dry weight which is defined as the post-dialysis body weight that allows the pre-dialysis blood pressure to remain normal without the need for anti-hypertensive drugs [27] [28]. The ideal allowable increase in dry weight and the appropriate target BP in children with ESKD is not known. Furthermore, age related changes in body composition make clinical assessment of volume status difficult [29]. Despite achievement of ideal dry weight, some patients remain hypertensive and other mechanisms for hypertension have been proposed in this population [30]-[32]. Furthermore, endothelial alterations, vascular smooth muscle hypertrophy and calcification occur in patients on chronic hemodialysis which perpetuate hypertension and increase cardiovascular morbidity and mortality [30] [33]. Evidence of uremic arteriopathy has also been demonstrated in children with ESKD [34] [35]. However, large volume ultra-filtration during hemodialysis in a short period of time, results in diminished cardiac filling, and decreased tolerance for dialysis [36]. Therefore, there are wide fluctuations in BP in children with ESKD on hemodialysis, making it difficult to define acceptable limits. In this cohort, fluid removal did have a significant effect on both SBP and DBP before the institution of bosentan. However 1 and 3 months after institution of bosentan, there were no significant changes in SBP after fluid removal indicating better tolerance of dialysis with no major fluctuations in blood pressure during dialysis. The use of an ET-1 receptor antagonist may therefore help maintain steady blood pressure. In this study, there was a higher trend in post-dialysis DBPs at 3 months post-initiation of bosentan, which may be related to volume contraction and vasoconstriction from rapid fluid removal [28].

Bosentan has been used in children with pulmonary hypertension and found to be efficacious and safe. In a large scale study involving 146 children, $2.7 \%$ of children $<12$ years had elevations in liver enzymes versus $7.8 \%$ of children $>12$ years [18]. This was reversible with dose modification or discontinuation of the drug. Therefore, liver enzymes have to be monitored in children receiving the drug. No specific side-effects were noted in our patients. The risk of pulmonary hypertension is significantly increased in ESKD and therefore treatment with bosentan could provide an added benefit in this population [37].

\section{Conclusion}

In conclusion, this preliminary report in children with ESKD suggests that bosentan is beneficial in the management of children with severe refractory hypertension. It has the potential to decrease cardiovascular morbidity and mortality associated with severe hypertension. The limitation of this study is that it is retrospective and uncontrolled. Bosentan was used as an adjunctive therapy and its isolated effect could not be determined. However, there was significant improvement in BP after institution of bosentan in this cohort of children who were refractory to multiple interventions. Although bosentan has been used for treatment of pediatric pulmonary hypertension, it has never been used for management of severe systemic hypertension in children. The strength of this study is that it provides impetus to consider future multi-centered prospective trials to evaluate the effi- 
cacy and safety of bosentan in the management of refractory systemic hypertension in children.

\section{Author(s) Conflict of Interest Statement}

The authors have no financial conflict of interest.

\section{References}

[1] Chavers, B.M., Li, S., Collins, A.J. and Herzog, C.A. (2002) Cardiovascular Disease in Pediatric Chronic Dialysis Patients. Kidney International, 62, 648-653. http://dx.doi.org/10.1046/j.1523-1755.2002.00472.x

[2] Mitsnefes, M. and Stablein, D. (2005) Hypertension in Pediatric Patients on Long-Term Dialysis: A Report of the North American Pediatric Renal Transplant Cooperative Study (NAPRTCS). American Journal of Kidney Diseases, 45 , 309-315. http://dx.doi.org/10.1053/j.ajkd.2004.11.006

[3] Chavers, B.M., Solid, C.A., Daniels, F.X., Chen, S.C., Collins, A.J., Frankenfield, D.L. and Herzog, C.A. (2009) Hypertension in Pediatric Long-Term Hemodialysis Patients in the United States. Clinical Journal of the American Society of Nephrology, 4, 1363-1369. http://dx.doi.org/10.2215/CJN.01440209

[4] Chavers, B. and Schnaper, H.W. (2001) Risk Factors for Cardiovascular Disease in Children on Maintenance Dialysis. Advances in Renal Replacement Therapy, 8, 180-190. http://dx.doi.org/10.1053/jarr.2001.26355

[5] Foley, R.N. and Parfrey, P.S., Harnett, J.D., Kent, G.M., Murray, D.C. and Barre, P.E. (1996) Impact of Hypertension on Cardiomyopathy, Morbidity and Mortality in End-Stage Renal Disease. Kidney International, 49, 1379-1385. http://dx.doi.org/10.1038/ki.1996.194

[6] Flynn, J.T., Mitsnefes, M., Pierce, C., Cole, S.R., Parekh, R.S., Furth, S.L. and Warady, B.A. (2008) Blood Pressure in Children with Chronic Kidney Disease: A Report from the Chronic Kidney Disease in Children Study. Hypertension, 52, 631-637. http://dx.doi.org/10.1161/HYPERTENSIONAHA.108.110635

[7] Halbach, S.M., Martz, K., Mattoo, T. and Flynn, J. (2012) Predictors of Blood Pressure and Its Control in Pediatric Patients Receiving Dialysis. Journal of Pediatrics, 160, 621-625. http://dx.doi.org/10.1016/j.jpeds.2011.09.046

[8] Schwarz, E.R., Heintz, B., Stefanidis, I., vom Dahl, J. and Sieberth, H.G. (2000) The Heterogeneous and Delayed Course of Blood Pressure Normalization in Hypertensive Patients after Bilateral Nephrectomy with and without Subsequent Renal Transplantation. Renal Failure, 22, 591-604. http://dx.doi.org/10.1081/JDI-100100900

[9] Seguias, L., Zilleruelo, G., Strauss, J., Abitbol, C. and Montane, B. (2001) Angiotensin-II and Endothelin-1 Levels in Children with Renoprival Hypertension. Pediatric Nephrology, 16, 493-496. http://dx.doi.org/10.1007/s004670100579

[10] Mailloux, L.U. and Haley, W.E. (1998) Hypertension in the ESRD Patient: Pathophysiology, Therapy, Outcomes, and Future Directions. American Journal of Kidney Diseases, 32, 705-719. http://dx.doi.org/10.1016/S0272-6386(98)70146-5

[11] Dinh, D.T., Frauman, A.G., Johnston, C.I. and Fabiani, M.E. (2001) Angiotensin Receptors: Distribution, Signalling and Function. Clinical Science (London), 100, 481-492. http://dx.doi.org/10.1042/CS20000263

[12] Moreau, P., D’Uscio, L.V., Shaw, S., Takase, H., Barton, M. and Lüscher, T.F. (1997) Angiotensin II Increases Tissue Endothelin and Induces Vascular Hypertrophy_Reversal by ETA-Receptor Antagonist. Circulation, 96, 1593-1597. http://dx.doi.org/10.1161/01.CIR.96.5.1593

[13] Krum, H., Viskoper, R.J., Lacourciere, Y., Budde, M. and Charlon, V. (1998) The Effect of an Endothelin-Receptor Antagonist, Bosentan, on Blood Pressure in Patients with Essential Hypertension. Bosentan Hypertension Investigators. New England Journal of Medicine, 338, 784-790. http://dx.doi.org/10.1056/NEJM199803193381202

[14] Henderson, L.W. (1980) Symptomatic Hypotension during Hemodialysis. Kidney International, 17, 571-576. http://dx.doi.org/10.1038/ki.1980.67

[15] (2004) The Fourth Report on the Diagnosis, Evaluation, and Treatment of High Blood Pressure in Children and Adolescents. Pediatrics, 114, 555-576. http://dx.doi.org/10.1542/peds.114.2.S2.555

[16] Chandar, J. and Zilleruelo, G. (2012) Hypertensive Crisis in Children. Pediatric Nephrology, 27, 741-751. http://dx.doi.org/10.1007/s00467-011-1964-0

[17] National Kidney Foundation (2005) KDOQI Clinical Practice Guidelines for Bone Metabolism and Disease in Children with Chronic Kidney Disease. American Journal of Kidney Diseases, 46, 12-100. http://www.kidney.org/professionals/kdoqi/guidelines_pedbone/index.htm

[18] Khoury, P.R., Mitsnefes, M., Daniels, S.R. and Kimball, T.R. (2009) Age-Specific Reference Intervals for Indexed Left Ventricular Mass in Children. Journal of the American Society of Echocardiography, 22, 709-714. http://dx.doi.org/10.1016/j.echo.2009.03.003

[19] Beghetti, M., Hoeper, M.M., Kiely, D.G., Carlsen, J., Schwierin, B., Segal, E.S. and Humbert, M. (2008) Safety Expe- 
rience with Bosentan in 146 Children 2 - 11 Years Old with Pulmonary Arterial Hypertension: Results from the European Postmarketing Surveillance Program. Pediatric Research, 64, 200-204.

http://dx.doi.org/10.1203/PDR.0b013e318179954c

[20] Dhaun, N., Goddard, J. and Webb, D. (2006) The Endothelin System and Its Antagonism in Chronic Kidney Disease. Journal of the American Society of Nephrology, 17, 943-955. http://dx.doi.org/10.1681/ASN.2005121256

[21] Schiffrin, E.L., Deng, L.Y., Sventek, P. and Day, R. (1997) Enhanced Expression of Endothelin-1 Gene in Endothelium of Resistance Arteries in Severe Human Essential Hypertension. Journal of Hypertension, 15, 57-63. http://dx.doi.org/10.1097/00004872-199715010-00005

[22] Li, J.S., Larivière, R. and Schiffrin, E.L. (1994) Effect of a Nonselective Endothelin Antagonist on Vascular Remodeling in Deoxycorticosterone Acetate-Salt Hypertensive Rats. Evidence for a Role of Endothelin in Vascular Hypertrophy. Hypertension, 24, 183-188. http://dx.doi.org/10.1161/01.HYP.24.2.183

[23] Larivière, R., Deng, L.Y., Day, R., Sventek, P., Thibault, G. and Schiffrin, E.L. (1995) Increased Endothelin-1 Gene Expression in the Endothelium of Coronary Arteries and Endocardium in the DOCA-Salt Hypertensive Rat. Journal of Molecular and Cellular Cardiology, 27, 2123-2131. http://dx.doi.org/10.1016/S0022-2828(95)91263-0

[24] Ergul, S., Parish, D.C., Puett, D. and Ergul, A. (1996) Racial Differences in Plasma Endothelin-1 Concentrations in Individuals with Essential Hypertension. Hypertension, 28, 652-655. http://dx.doi.org/10.1161/01.HYP.28.4.652

[25] Sfikakis, P.P., Papamichael, C., Stamatelopoulos, K.S., Tousoulis, D., Fragiadaki, K.G., Katsichti, P., Stefanadis, C. and Mavrikakis, M. (2007) Improvement of Vascular Endothelial Function Using the Oral Endothelin Receptor Antagonist Bosentan in Patients with Systemic Sclerosis. Arthritis \& Rheumatism, 56, 1985-1993. http://dx.doi.org/10.1002/art.22634

[26] Wolf, S.C., Sauter, G., Risler, T. and Brehm, B.R. (2005) Effects of Combined Endothelin and Angiotensin II Antagonism on Growth Factor-Induced Proliferation of Vascular Smooth Muscle Cells Isolated from Uremic Rats. Renal Failure, 27, 465-474. http://dx.doi.org/10.1081/jdi-65421

[27] Charra, B. and Chazot, C. (2003) Volume Control, Blood Pressure and Cardiovascular Function. Lessons from Hemodialysis Treatment. Nephron Physiology, 93, 94-101. http://dx.doi.org/10.1159/000070242

[28] Stegmayr, B.G. (2003) Ultrafiltration and Dry Weight-What Are the Cardiovascular Effects? Artificial Organs, 27, 227-229. http://dx.doi.org/10.1046/j.1525-1594.2003.07205.x

[29] Foster, B.J. and Leonard, M.B. (2004) Measuring Nutritional Status in Children with Chronic Kidney Disease. American Journal of Clinical Nutrition, 80, 801-814.

[30] Van Buren, P.N. and Inrig, J.K. (2012) Hypertension and Hemodialysis: Pathophysiology and Outcomes in Adult and Pediatric Populations. Pediatric Nephrology, 27, 339-350. http://dx.doi.org/10.1007/s00467-011-1775-3

[31] Carlini, R., Obialo, C.I. and Rothstein, M. (1993) Intravenous Erythropoietin (rHuEPO) Administration Increases Plasma Endothelin and Blood Pressure in Hemodialysis Patients. American Journal of Hypertension, 6, 103-107.

[32] Pearl, R.J., Papageorgiou, P.C., Goldman, M., Amfilochiadis, A.A., Boomsma, F., Rojkjaer, R., Geary, D. and Osmond, D.H. (2003) Possible Role of New Pressor Protein in Hypertensive Anephric Hemodialysis Patients. Pediatric Nephrology, 18, 1025-1031. http://dx.doi.org/10.1007/s00467-003-1246-6

[33] Morris, S.T., McMurray, J.J., Spiers, A. and Jardine, A.G. (2001) Impaired Endothelial Function in Isolated Human Uremic Resistance Arteries. Kidney International, 60, 1077-1082. http://dx.doi.org/10.1046/j.1523-1755.2001.0600031077.x

[34] Litwin, M., Wühl, E., Jourdan, C., Niemirska, A., Schenk, J.P., Jobs, K., Grenda, R., Wawer, Z.T., Rajszys, P., Mehls, O. and Schaefer, F. (2008) Evolution of Large-Vessel Arteriopathy in Paediatric Patients with Chronic Kidney Disease. Nephrology Dialysis Transplantation, 23, 2552-2557. http://dx.doi.org/10.1093/ndt/gfn083

[35] Shroff, R.C., Donald, A.E., Hiorns, M.P., Watson, A., Feather, S., Milford, D., Ellins, E.A., Storry, C., Ridout, D., Deanfield, J. and Rees, L. (2007) Mineral Metabolism and Vascular Damage in Children on Dialysis. Journal of the American Society of Nephrology, 18, 2996-3003. http://dx.doi.org/10.1681/ASN.2006121397

[36] Miltényi, G., Tory, K., Stubnya, G., Tóth-Heyn, P., Vásárhelyi, B., Sallay, P., Szabó, A., Tulassay, T., Dobos, M. and Reusz, G.S. (2001) Monitoring Cardiovascular Changes during Hemodialysis in Children. Pediatric Nephrology, 16, 19-24. http://dx.doi.org/10.1007/s004670000497

[37] Ramasubbu, K., Deswal, A., Herdejurgen, C., Aguilar, D. and Frost, A.E. (2010) A Prospective Echocardiographic Evaluation of Pulmonary Hypertension in Chronic Hemodialysis Patients in the United States: Prevalence and Clinical Significance. International Journal of General Medicine, 5, 279-286. 


\section{Abbreviations}

ESKD: end stage kidney disease;

BP: blood pressure;

SBP: systolic blood pressure;

DBP: diastolic blood pressure;

LVMI: left ventricular mass index;

LVH: left ventricular hypertrophy;

PTH: intact parathyroid hormone;

FSGS: focal segmental glomerulosclerosis. 